\title{
Rowan University and La Universidad de La Serena: An International Collaboration for Teaching and Research
}

\author{
Z. Otero Gephardt", José O. Valderrama and Carolina Ponce \\ Dept. of Chemical Engineering, Rowan University, Glassboro, NJ / Dept. of \\ Mechanical Engineering, La Universidad de La Serena, La Serena, Chile \\ * to whom correspondence should be addressed
}

abstract

Rowan University in Glassboro, NJ and La Universidad de La Serena in La Serena, Chile have recently entered into a general agreement that will allow for a wide range of options for students and faculty in both universities. Both universities are of similar size and serve similar types of students. The general agreement includes student and faculty exchanges, research opportunities and collaborations in the development and exchange of teaching methods. It is a great benefit to students and faculty in both universities. The agreement can serve as a template for international collaborations between institutions in the United States and Latin America.

A research project involving supercritical fluid extraction of a salmon food additive from micro algae is currently underway. The additive, astaxanthin, is a natural pigment and antioxidant. Chile is the second largest exporter of salmon in the world, second only to Norway. A junior/senior level engineering clinic has been jointly developed for the Control and Dynamics course in the Mechanical Engineering Department at the Universidad de La Serena. Engineering clinics were first developed at Rowan University. Students take an engineering clinic course every semester and work on projects in their junior and senior years. Some of these projects can relate directly to courses or be industrial projects funded by regional and national companies. International collaborations offer students an excellent opportunity to experience the global interactions and technology exchanges. This is becoming more important as engineers are more involved in the dynamics of the global economy.

introduction and background

Rowan University, as all institutions of higher education in the United States, strives to provide a well rounded engineering education. A well rounded education that includes a strong liberal arts component and communication results in more creative engineers with solid ethics and a true understanding of how their work impacts the community. The community that engineers serve has become broader and more diverse with time. There is very little engineering work today that does not have a global impact. This has resulted in a stronger need to include a global component in engineering education. In recognition of this increasing need, Rowan University has recently established an International Center with the understanding that we all gain when we learn from each other and not simply export technology to less developed countries. The International Center promotes the study abroad concept but it also includes faculty and student exchanges, research and teaching. These activities are implemented at the Rowan Campus or at 
campuses throughout the world by Rowan faculty and students. Some of these activities are combined with international initiatives such as the recently formed chapter of Engineers Without Borders at Rowan. The concept of international cooperation is not new. What is new is the identification and implementation of international opportunities from an interdependent perspective. The global economy has dictated this new thinking and engineers are especially suited to the task. Engineers develop and use technology for the betterment of humanity. Thus, calls for engineering curriculum renewal, now are likely to include a focus on developing world class engineers, meaning engineers with an understanding of the complexities in a global economy. ${ }^{1-4}$ In addition, US schools are finding that taking American engineering education overseas can make a significant international contribution and be good business. ${ }^{5}$

There are numerous study abroad and international programs throughout the United States and the world. Noteworthy are programs with a well defined mission and focus. ${ }^{6}$ Engineers are problem solvers and uniquely equipped to handle challenges that can reduce poverty and starvation and improve human health throughout the world. The Engineers Without Frontiers Program focuses on sustainable development to improve the quality of life. ${ }^{6}$ The program sends engineering students throughout the world to work on a wide range of projects. Students gain significant technical understanding and learn that the most elegant solution is the one that works within the budgetary and time constraints of the project, not necessarily the most "high-tech." They are exposed to the idea that if we help the 5 million people who live on $\$ 3 /$ week or less or the 1.2 billion people that do not have access to clean drinking water, we all benefit. In addition to improving the quality of life and solving interesting technical problems, students are helping to develop potential employees for a wide range of industries and potential customers for our products.

The globalization of engineering education is essential to support a global economy. The UNESCO Center for Engineering Education is an excellent model and illustrates the important connection between a global education and a profitable global economy. ${ }^{7}$ The Center serves as a national and international clearing house for the transfer of information on engineering education. International activities can also play a role in enhancing global security. For example, there is a need for strengthening the safety of radiation sources and the security of radioactive materials. ${ }^{8}$ The globalization of engineering education can enhance the international collaborations in this area. This could result in improved use of these materials for peaceful purposes and in the enhancement of sustainable development activities throughout the world.

Collaborations between Rowan University and the Universidad de La Serena began during the Summer of 2002. During this summer, one of the authors (Gephardt) was invited to present some technical work in the area of Experimental Design, engineering clinic pedagogy and engineering education accreditation. Engineering clinics are project based engineering courses required every semester in the Rowan University curriculum. These courses focus on teamwork and are often projects funded by regional industry. A meeting with Jaime Pozo Cisternas, President of the Universidad de La Serena, led to the possibility for further collaboration. An original agreement (Convenio Marco) was drafted and brought to Rowan University for consideration. The agreement was translated, reviewed and edited with the assistance of the International Center at Rowan University and the International Office at the Universidad de La Serena. The Universidad de La Serena and Rowan University share several characteristics. They 
both have approximately 10,000 students. They have colleges of engineering and strong liberal arts programs. They are both located in small towns and serve numerous students from working class families who may be the first to attend college. The Universidad de La Serena does not have a chemical engineering department but has strong chemical engineering components in its Mechanical Engineering Department. The Universidad de La Serena is at a critical stage in its development. There are numerous programs seeking accreditation and there is a willingness to consider novel teaching and research methodologies. The university calendars also allow for interesting cooperation during the North American summer months. Since the Fall semester in La Serena runs during the Summer in the United States, students can participate in projects or take courses in La Serena during the summer with minimum disruption to their academic programs at Rowan. The Memorandum of Agreement provides a vehicle of mutual benefit that will serve to enhance the education, research and faculty and student development opportunities in both Universities.

\section{The Memorandum of Agreement}

The Memorandum of Agreement is a general document and forms the foundation of all specific agreements covering specific projects and activities between the universities. It covers activities that include student and faculty exchanges, collaborative research projects and academic activities such as courses, conferences and seminars, and interchange and collaboration in cultural projects. The Agreement specifies that the presidents of both universities appoint a Commission with equal number of members from each institution. The Commission is the planning, monitoring, and evaluating body for all activities related to the Agreement and any agreements related to specific projects. The Commission also reviews and resolves any disagreements regarding projects governed by the Agreement. Presently, the Commission includes the directors of the International Offices in both Universities and two of the authors (Gephardt and Valderrama), and will meet as needed.

The Agreement defines the format for all agreements for specific projects and/or activities. Each specific agreement must include the following.

- Definition of objectives

- Description of the program with details regarding the phases of the program

- Formulation and approval of the project

- Roles of each participant in the project

- Establishment of procedures for publication, acknowledgments, and handling of intellectual property in the case of joint research

- Any other matters relevant to the parties involved in the program

All specific agreements covered by the Memorandum of Agreement will be limited to administrative matters and not address any labor or labor relations matters. This is especially important since labor practices in each institution are different. These matters are handled by each University individually.

The Memorandum of Agreement was signed by the presidents of both universities in English and Spanish. The format of this Agreement has important benefits. First, it sets the foundation for 
any specific agreements covering future projects and collaborations between both universities. It specifies the format for all future agreements and it has built in monitoring and assessment through the creation of the Commission. Another important aspect of the agreement is the role of the Commission as a means for conflict resolution. By having a means for resolution before conflict starts, there is more confidence that any possible differences can be handled equitably.

collaborative projects

The agreement was signed and became effective in November 2004. Since that time, there are two projects under development. Rowan University is using Chilean microalgae to study the supercritical fluid extraction of the carotenoid astaxanthin. Astaxanthin is a powerful antioxidant. It is 100 times more powerful than vitamin E. It can also be used as a pigment for farmed salmon. Chile is the world's second largest salmon exporter (second to Norway).

Finding inexpensive and natural food supplements that improve the health and marketability of the fish is very important to the salmon industry. Supercritical fluid extraction with $\mathrm{CO}_{2}$ may provide a natural and inexpensive green alternative to conventional extraction methods and to synthetic astaxanthin. Synthetic astaxanthin is not absorbed by the fish as well as the natural product. In addition, artificial fish colorants may be responsible for allergic reactions in humans. To date, the team at Rowan University has reproduced some preliminary results obtained by the University of La Serena. The governing mechanism for the extraction has been identified and experiments are underway to study co-solvents for enhanced extraction efficiency.

An engineering clinic is being developed by Rowan University and the Universidad de La Serena faculty. The engineering clinic will be part of the Control and Dynamics course in the Mechanical Engineering Department at the Universidad de La Serena. The control experiment involves automated welding and has been part of the course for several years. This experiment was originally designed by one of the authors (Ponce). The engineering clinic will include written and oral communication modules. Students will study the welding process and become familiar with the automation. They will write a manual for the experiment and specify the experimental conditions. They will run the experiments and report their findings in writing and via an oral presentation to the class. Rowan University faculty along with faculty from the Mechanical Engineering and Communication (Humanities Faculty) Departments in La Serena will design and implement the clinic. The entire module is expected to take three weeks. This is different from semester long engineering clinics at Rowan University. The goal is to provide a pilot clinic that can be assessed easily so that future clinics can be designed and implemented.

In addition, as a result of the collaboration between the universities, the Departments of Music at Rowan and La Serena have begun negotiations for a student exchange. The first student from the Universidad de La Serena is expected at Rowan before the end of January.

conclusions

The globalization of engineering education will be an important contributor to the global economy. There are numerous benefits to international collaborations. The most important is to develop students with a world view who can be the creative problem solvers of the future. The Memorandum of Agreement between Rowan University and the Universidad de La Serena 
includes important aspects that set the foundation for future agreements for specific projects. The Agreement specifies the format of all future specific agreements and provides for the assessment of projects and conflict resolution. The Agreement has generated significant interest in both universities and collaborative projects are underway. The Memorandum of Agreement will enhance scholarly and pedagogical activities and faculty and student development opportunities.

\section{acknowledgments}

The authors gratefully acknowledge the contributions of Dr. Edward Smith, Interim Director of the International Center at Rowan University, and Julio Parada Pizarro, Director of the International Office at la Universidad de La Serena.

Bibliography

1. Wormley, D.N., Challenges in Curriculum Renewal, Ibid,_20(3), pp329-332, 2004.

2. Pasek, Z.J., Y. Koren and S. Segall, Manufacturing in a Global Context: A Graduate Course on Agile Reconfigurable Manufacturing, The International Journal of Engineering Education, 2(5), pp742-753, 2004.

3. Sin, K.W.M, Cultural Studies in the Engineering Curriculum, The International Journal of Engineering Education, 19(6), pp.855-861, 2003.

4. Fruchter, R. and A. Townsend, Multi-Cultural Dimensions and Multi-Modal Communication in Distributed Cross Disciplinary Teamwork, International Journal of Engineering Education, 19(1), 2003.

5. Grose, T.K., Staying Home, Prism, 11(2), 2001.

6. Grose, T.K., A World Class Act, Prism, 14(1), p. 42, September 2004.

7. Pudlowski, Z.J. and P.L. Darvall, UICEE-a Path-Finding Enterprise in the Globalisation of Engineering Education, Global Journal of Engineering Education, I(1), 1997.

8. González, A.J., Strengthening the Safety of Radiation Sources and the Security of Radioactive Materials: Timely Action, IAEA Bulletin, 41(3), 1999.

biographical information

ZENAIDA OTERO GEPHARDT, PhD, P.E. is on the faculty of the Chemical Engineering Department of Rowan University where she has also served as Director and Assistant Dean of Engineering. She has teaching and research interests in process dynamics and control, process fluids transport and data analysis and experimental design.

JOSE O VALDERRAMA, PhD is Professor of Mechanical Engineering at La Universidad de La Serena, La Serena, Chile where he has also served as department chair. He has teaching and research interests in thermodynamics, fluid mechanics and process optimization.

CAROLINA PONCE is Assistant Professor of Mechanical Engineering at La Universidad de La Serena, La Serena, Chile Her area of research and teaching interest is process control. 
